

\title{
Decolorization of Methylene Blue from Aqueous Solution \\ Using Mg-Fe-Al Layered Double Hydroxides with $\mathrm{H}_{2} \mathrm{O}_{2}$
}

\author{
Nguyen Tien Thao* and Do Thi Trang
}

Faculty of Chemistry, VNU University of Science, Vietnam National University, 19-Le Thanh Tong ST, Hanoi, Vietnam

*Corresponding author: Fax: +84 4 38241140; Tel: +84 4 39331605; E-mail: ntthao@vnu.edu.vn

\begin{abstract}
A series of $\mathrm{Mg}-\mathrm{Fe}-\mathrm{Al}$ layered double hydroxides (LDHs) with different ratios of $\mathrm{Mg} /((\mathrm{Fe}+\mathrm{Al})$ has been prepared and characterized by XRD, FT-IR. BET, SEM and TEM. The experimental data indicated that all the samples present a well-structured hydrotalcite, uniform particles or palettes and layered structures. The synthesized materials have used as catalysts/adsorbents for the decolorization of methylene blue in water. The preliminary results showed that Fe-containing hydrotalcites play as an active catalyst for the oxidation of methylene blue while the Fe-free sample acts as an adsorbent. The methylene blue conversion obtained over $\mathrm{Mg}$-Fe- $\mathrm{Al}$ hydrotalcites was $c a$. 50 $55 \%$ at an ambient condition, but significantly improved as treated at a higher temperature or under UV light. The conversion of methylene blue approaches $c a .75-90 \%$ under UV-light or higher temperature.
\end{abstract}

Key Words: Hydrotalcite, Methylene blue, Layered structure, Degradation, Decolorization.

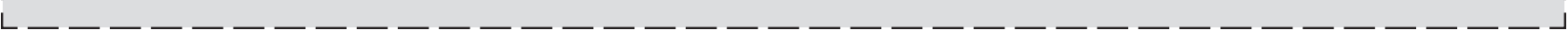

\section{INTRODUCTION}

Layered double hydroxides (LDH) or hydrotalcite, also classified to the type of anionic clays, are basic solid materials formed by divalent metal cation hydroxide layers with the brucite structure ${ }^{1,2}$.

Layered double hydroxides (LDH) or hydrotalcite, also classified to the type of anionic clays, are basic solid materials formed by divalent metal cation hydroxide layers with the brucite structure $^{1,2}$. The layers contain metal ions of at least two different oxidation states. The most common case of diand trivalent cations leads to the general chemical formula $\left[\mathrm{M}^{2+}{ }_{1-\mathrm{x}} \mathrm{M}^{3+}{ }_{\mathrm{x}}(\mathrm{OH})_{2}\right]^{\mathrm{x}+}\left(\mathrm{A}^{\mathrm{n}-}\right)_{\mathrm{x} / \mathrm{n}} \cdot \mathrm{yH}_{2} \mathrm{O}$ where $\mathrm{x}$ refers to the $\mathrm{M}^{3+} /\left(\mathrm{M}^{2+}\right.$ $+\mathrm{M}^{3+}$ ) ratio ranging between 0.25 and 0.4 . Due to the replacement of $\mathrm{Mg}^{2+}$ by a trivalent ion, the network would not balance the charge and appear a positively charge in the brucite sheet. Therefore, anions $\mathrm{A}^{\mathrm{n}-\mathrm{r}}$ like carbonate, sulfate, phosphate, nitrate, chloride, etc. are intercalated in the interlayer section of the clay structure ${ }^{1,3,4}$. By this way, a large number of layered double hydroxides were prepared by changes in the ratio of $\mathrm{Mg}^{2+} / \mathrm{M}^{3+}$ or the exchanges of anions. These derived hydrotalcites are designed for the adaptation of the application purposes $^{2-9}$. For some typical examples, $\mathrm{Mg}-\mathrm{Al}-\mathrm{CO}_{3}$ like hydrotalcites was used as basic catalysts for the Hantzsch pyridine synthesis ${ }^{3}$, aldol condensation ${ }^{4,5}$. Mg-Al-molybdate layered double hydroxide prepared by the exchange of anion carbonates with molybdate is an active catalyst for dehydro- genation of propane ${ }^{6}$. In other context, substitution of di- or trivalent metal cation in the hydroxide sheets can also produce many deriving hydrotalcites that can be used as active oxidation/ reduction catalysts ${ }^{7}$. Indeed, $\mathrm{Mg}-\mathrm{Ni}-\mathrm{Al}$ hydrotalcites are rather active for the partial oxidation of light paraffins ${ }^{8}$; steam reforming of alcohols ${ }^{9,10}$. Mg-Mn(Fe)-Al layered double hydroxides worked well for the oxidation of alkylaromatics ${ }^{11,12}$; $\mathrm{Mg}-\mathrm{Zn}-\mathrm{Al}$ hydrotalcite-like materials are applied for the epoxidation of unsaturated hydrocarbons ${ }^{13,14}$. This article reports the catalytic activity of different Fe-Mg-Al hydrotalcite catalyst in the decolorization of aqueous methylene blue solution.

\section{EXPERIMENTAL}

Preparation and characterization of the catalysts: A stoichiometric amount of sodium carbonate was dissolved in $25 \mathrm{~mL}$ of water in a $500 \mathrm{~mL}$-beaker. The solution was heated to $60-65^{\circ} \mathrm{C}$. Then, a quantity of aluminum nitrate nonahydrate and magnesium nitrate hexahydrate, iron(III) nitrate nonanhydrate were dissolved in $150 \mathrm{~mL}$ of distilled water. The $\mathrm{pH}$ of the solution was adjusted to $9.5 \mathrm{using} 1.5 \mathrm{M} \mathrm{NaOH}$ and was kept for $24 \mathrm{~h}$. The precipitate was filtered, washed and dried at $80^{\circ} \mathrm{C}$.

Powder X-ray diffraction (XRD) patterns were recorded on a D8 Advance-Bruker instrument using $\mathrm{CuK}_{\alpha}$ radiation $(\lambda$ $=1.59 \mathrm{~nm}$ ). Fourier transform infrared (FT-IR) spectrum was 
obtained in 4000-400 $\mathrm{cm}^{-1}$ range on a FT/IR spectrometer (DXPerkin Elmer, USA). The scanning electron microscopy (SEM) microphotographs were obtained in a JEOS JSM-5410 LV. TEM image was collected on a Japan Jeol. Jem.1010. The nitrogen physisorption was measured at $77 \mathrm{~K}$ on an Autochem II 2920 (USA).

Decolorization of aqueous methylene blue: $0.20 \mathrm{~g}$ of hydrotalcite catalyst and $3 \mathrm{~mL}$ of $30 \% \mathrm{H}_{2} \mathrm{O}_{2}$ were added into $200 \mathrm{~mL}$ methylene blue solution with $3000 \mathrm{ppm}$. The suspension was stirred at room temperature under solar light for a period of time. Then, the resultant was filtered. The leaching solution was used for absorbance measurement at the characteristic absorption wavelength of methylene blue, $664 \mathrm{~nm}$. Removal per cent of methylene blue was calculated from initial and remaining concentration of reactant using the absorbance recorded absorbance on a UV-VIS spectrophotometer (72Shanghai, China) at $665 \mathrm{~nm}$ before and after the reaction. After the determination of the residual methylene blue concentration $(\mathrm{C})$ the conversion was calculated following the equation below:

$$
\text { Conversion }=\frac{\left(\mathrm{C}^{0}-\mathrm{C}\right)}{\mathrm{C}^{0}} \times 100
$$

where $\mathrm{C}^{0}$ is the initial aqueous methylene blue concentration, $\mathrm{C}$ is the methylene blue concentration after the experiment.

\section{RESULTS AND DISCUSSION}

X-Ray diffraction: The phase of three layered double hydroxides is determined by X-ray diffraction in Fig. 1. XRD patterns appear the sharp and symmetric reflection peaks at $2 \theta$ of $23.5 ; 34.9 ; 39.6 ; 47.1 ; 60.8$ and $62.3^{\circ}$, characterizing to the typical planes of (006); (012); (015); (018); (110); (113) for the typically layered double hydrotalcite structure ${ }^{1,5,7,15}$. No observable reflection signals of iron oxides are detected over Fe-containing hydrotalcite samples, indicating the isomorphical substitution of $\mathrm{Mg}^{2+}$ by cations $\mathrm{Fe}^{3+}$ in the hydroxide layers structure although the exact oxidation number of ionic iron in the lattice is still a subject of research ${ }^{1,15,16}$.

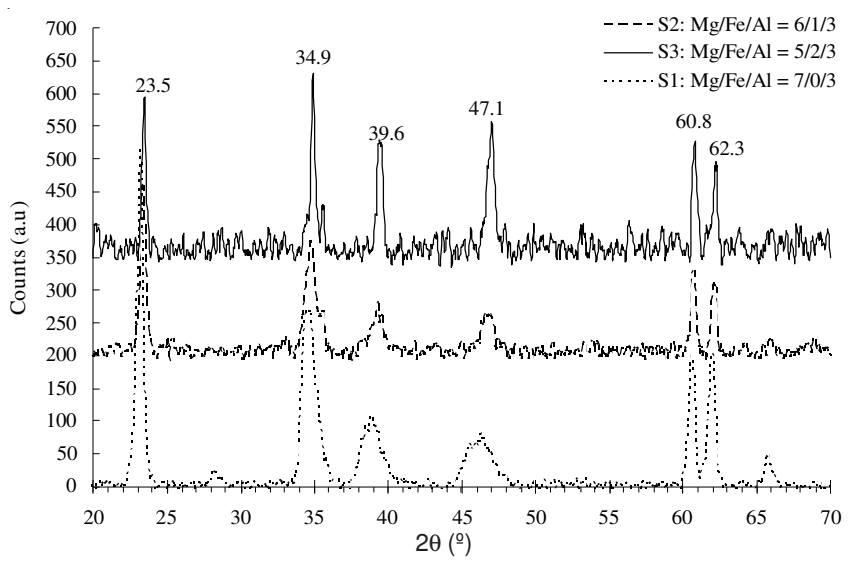

Fig. 1. XRD patterns for Mg-Fe-Al layered double hydroxides

Moreover, no remarkable changes in the X-ray reflection positions (2 $\theta$ ) between XRD pattern for $\mathrm{Mg}$ - $\mathrm{Al}$ hydrotalcite and $\mathrm{Mg}-\mathrm{Fe}-\mathrm{Al}$ sample with increasing $\mathrm{Mg}^{2+} /\left(\mathrm{Fe}^{3+}+\mathrm{Al}^{3+}\right)$ ratio in layered double hydroxides. This can be understandable because of a resemblance in ionic radius between $\mathrm{Mg}^{2+}(0.65$ $\mathrm{nm})$ and $\mathrm{Fe}^{3+}(0.64 \mathrm{~nm})$ cations $^{8,10,13,15,16}$. However, Fig. 1 also indicates a decrease in the full width at half maximum (FWHM) peaks over the Fe-containing hydrotalcite, suggesting larger hydrotalcite crystal domains obtained on such $\mathrm{Mg}-\mathrm{Fe}-\mathrm{Al}$ samples. In addition, at a higher Fe content, XRD pattern shows a high signal-to-noise ratio, suggesting the presence of a small amount of amorphous oxides in addition to hydrotalcite crystal $^{1,16}$.

FT-IR spectra: FTIR spectra of Fe-free hydrotalcite sample and $\mathrm{Mg}-\mathrm{Fe}-\mathrm{Al}-\mathrm{CO}_{3}$ layered hydrotalcite are typical characteristics of hydrotalcites, in good accordance with the data reported in literature $e^{1,2,5,6,9,12,16,17}$. As presented in Fig. 2, IR spectra of two layered double hydroxides show the characteristic absorption bands of a hydroxyl group. A broad band at $3420 \mathrm{~cm}^{-1}$ is attributed to the stretching vibrations of the hydroxyls attached to $\mathrm{Al}-$ and $\mathrm{Mg}$ - sheets and to water molecules in the basal interlayer ${ }^{5,9,18}$. A visible shoulder near 3060 $\mathrm{cm}^{-1}$ is ascribed to the interaction between the $\mathrm{OH}$ groups and the interlayer carbonate ions. Week signals at 2212 and 1662 $\mathrm{cm}^{-1}$ are assigned to the $\mathrm{H}_{2} \mathrm{O}$ bending vibration of interlayer water ${ }^{18,19}$. The band appears at $1365 \mathrm{~cm}^{-1}$ is attributed to the vibration of interlayer carbonate species. A number of bands in the range of $440-750 \mathrm{~cm}^{-1}$ are assigned to the metaloxygen-metal stretching modes ${ }^{7,19}$, with an exception of the band at $671 \mathrm{~cm}^{-1}$ considered as the signal of $\mathrm{CO}_{3}{ }^{2-}$ present in the interlayer ${ }^{19-22}$.

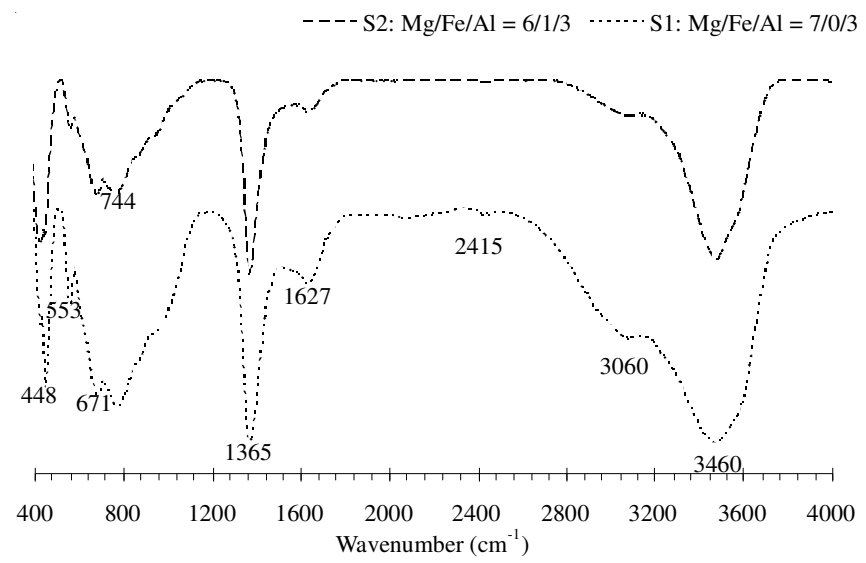

Fig. 2. FT-IR spectra for $\mathrm{Mg}-\mathrm{Fe}-\mathrm{Al}$ layered double hydroxides

As seen in Fig. 2, the hydroxyl stretching region and the metal bands below $1000 \mathrm{~cm}^{-1}$ in the Fe-containing hydrotalcite appear narrower than those in the $\mathrm{Fe}$-free sample ${ }^{23}$, reflecting the presence of a smaller crystal domain as consistent with the XRD observation ${ }^{9,13,16}$.

Microscopic examination: Fig. 3 represents three SEM pictures and a TEM image of some representative samples. Under a similar magnification scale, SEM micrographs indicate a slight variation in the particle size with the Fe content in the synthesized $\mathrm{Mg}-\mathrm{Fe}-\mathrm{Al}$ hydrotalcites. This observation is in good agreement with what is interpreted from the full width at half maximum in Fig. 1. Fig. 3A shows uniform rhombohedral-shaped particles with the length $\mathrm{x}$ width in the order of $50 \mathrm{~mm} \times 30 \mathrm{~nm}$ for Fe-free sample. An insertion of iron(III) cations in to the brucite sheet results in an observable change 


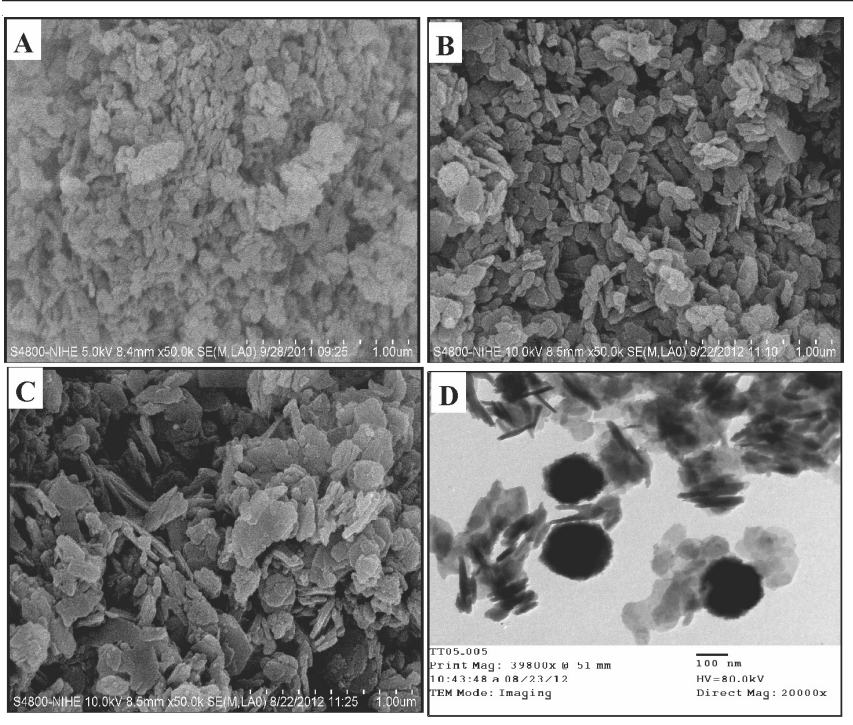

Fig. 3. SEM photographs of $\mathrm{Mg} / \mathrm{Fe} / \mathrm{Al}=7 / 0 / 3$ (A); $\mathrm{Mg} / \mathrm{Fe} / \mathrm{Al}=6 / 1 / 3$ (B); $\mathrm{Mg} / \mathrm{Fe} / \mathrm{Al}=5 / 2 / 3$ (C) and TEM image $\mathrm{Mg} / \mathrm{Fe} / \mathrm{Al}=5 / 2 / 3$ (D)

in the average particle sizes ${ }^{4,15,18}$. As seen in Fig. 2, the particle diameter of $\mathrm{Mg} / \mathrm{Fe} / \mathrm{Al}=6 / 1 / 3$ sample is larger than that of the $\mathrm{Fe}$-free hydrotalcite. Moreover, is still consisted of agglomerates in some parts ${ }^{1,9,10,18,19}$ (Fig. 3B).

Following the trend in increasing Fe content, it is expected that the catalyst domain of the Fe-richer-layered double hydroxide would be growth. Fig. 3C shows the presence of hydrotalcite plate-like shapes instead of tiny particles. The palette size varies from several dozen to some hundred nanometers as observed in its TEM image ${ }^{20,21}$. Fig. 3D represents a TEM photograph of the Fe-richer-sample $(\mathrm{Mg} / \mathrm{Fe} / \mathrm{Al}$ $=5 / 2 / 3)$. Careful examination of TEM image reveals the hydrotalcite palettes possess lamellar structure, which is represented by the appearance of dark lines in parallel ${ }^{21}$. In addition, the palettes arrange in disordered ways to produce many voids which are likely open pores ${ }^{22}$. An examination of nitrogen sorption would corroborate this hypothesis

Nitrogen adsorption/desorption: A careful analysis of nitrogen adsorption-desorption isotherms of three synthesized hydrotalcite samples indicates that the textural properties of $\mathrm{Mg}-\mathrm{Fe}-\mathrm{Al}$ layered double hydroxides were associated with the chemical composition. In practical, the BET specific surface areas of the Fe-free-layered double hydroxide has a BET value of $84.3 \mathrm{~m}^{2} / \mathrm{g}$, on a par with that of the iron-poor-sample $(\mathrm{Mg} /$ $\mathrm{Fe} / \mathrm{Mg}=6 / 1 / 3)$ while surface area of the Fe-richer-layered double hydroxide $\mathrm{Mg} / \mathrm{Fe} / \mathrm{Al}=5 / 2 / 3)$ ) reaches to a rather high value of $c a .198 .2 \mathrm{~m}^{2} / \mathrm{g}$ (Table-1). As shown in Fig. 4, the nitrogen adsorption-desorption isotherms of the two former patterns can be classified as the intermediate type between types II and IV adsorption isotherms ${ }^{19,20,23}$, corresponding to the pores with narrow and wide sections and possible interconnecting channels. Moreover, the appearance of a thin hysteresis at high relative pressure indicates that these solids do not only have micropores, but also possess some mesopores and micropores.

Meanwhile, the Fe-rich-hydrotalcite $(\mathrm{Mg} / \mathrm{Fe} / \mathrm{Al}=5 / 2 / 3)$ displays a $\mathrm{H} 3$ hysteresis loop over the relative pressure range $0.30-0.95$ which is attributed mainly to aggregates of platelike particles leading to slit-like pores ${ }^{19,24,25}$. These slit-like
TABLE-1

NITROGEN ADSORPTION/DESORPTION PROPERTIES

\begin{tabular}{cccc}
\hline Sample & $\mathrm{Mg} / \mathrm{Fe} / \mathrm{Al}$ ratio & $\mathrm{S}_{\mathrm{BET}}\left(\mathrm{m}^{2} / \mathrm{g}\right)$ & Micropore volume $\left(\mathrm{cm}^{2} / \mathrm{g}\right)$ \\
\hline S1 & $7 / 0 / 3$ & 84.3 & 0.006244 \\
S2 & $6 / 1 / 3$ & 83.8 & 0.005537 \\
S3 & $5 / 2 / 3$ & 198.2 & 0.104682 \\
\hline
\end{tabular}

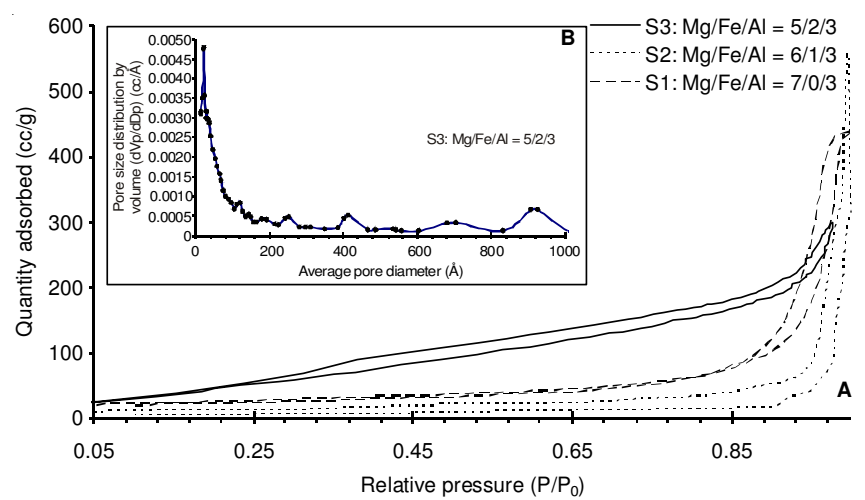

Fig. 4. Nitrogen adsorption/desorption curves on Mg-Fe-Al layered double hydrotalcites

capillaries cause the hysteresis during the nitrogen desorption process $^{2,7,23}$. Moreover, the solid contains not only mesopores, but also some micropores which is represented by a sharp increase in the amount of nitrogen adsorption in the range of relative low pressures ${ }^{23,24}$ (Table-1).

Decolorization of methylene blue in the presence of Mg-Fe-Al hydrotalcites: The decolorization of methylene blue from an aqueous solution has been investigated over three prepared $\mathrm{Mg}-\mathrm{Fe}-\mathrm{Al}$ hydrotalcites used hydrogen peroxide as an oxidant. Typically, all experiments were carried out with 3000 ppm of methylene blue, $3 \mathrm{~mL}$ of $\mathrm{H}_{2} \mathrm{O}_{2} 30 \%$ vol. \% under natural solar light with the exceptions indicated. First all, a blank test has done to examine the decolorization ability of methylene blue within $150 \mathrm{~min}$.

As shown in Fig. 5, the conversion of methylene blue gradually increases and reaches only $c a$. 10-14\% after 150 min. In this case, $\mathrm{H}_{2} \mathrm{O}_{2}$ acts as an oxidant to oxidize methylene blue, yielding a colorless product. As addition of layered double hydroxide into solution, the methylene blue conversion changes remarkably, depending on the catalyst composition and catalyst texture. For the Fe-free-sample conversion of varies significantly beginning reaction time and negligibly changes after $75 \mathrm{~min}$. We believe that in this case $\mathrm{Mg}$-Al hydrotalcite plays as an adsorbent to concentrate both methylene blue and hydroxide species on the porous catalyst surface. It is no doubt that the oxidation of methylene blue in aqueous solution takes place through several steps such as diffusion of reagents to the surface, adsorption on the surface, reaction on the surface, desorption of products and liberation of the adsorbed products ${ }^{26,27}$. Therefore, the reaction between $\mathrm{H}_{2} \mathrm{O}_{2}$ and/or oxidizing intermediate agent $\left(\mathrm{HO}^{\circ}\right)$ and methylene blue is facilitated when both reagents adsorbed on the Mg-Alhydrotalcite surface ${ }^{25,26,28,29}$. Therefore, the adsorption of methylene blue likely happens rapidly on the hydrotalcite catalysts, resulting in a sharp increase in methylene blue conversion on the $\mathrm{Mg}$-Al-hydrotalcite catalyst within 25 $\min ^{25,28}$. As introduction of $\mathrm{Fe}^{3+}$ into $\mathrm{Mg}$-Al hydrotalcite layers, 


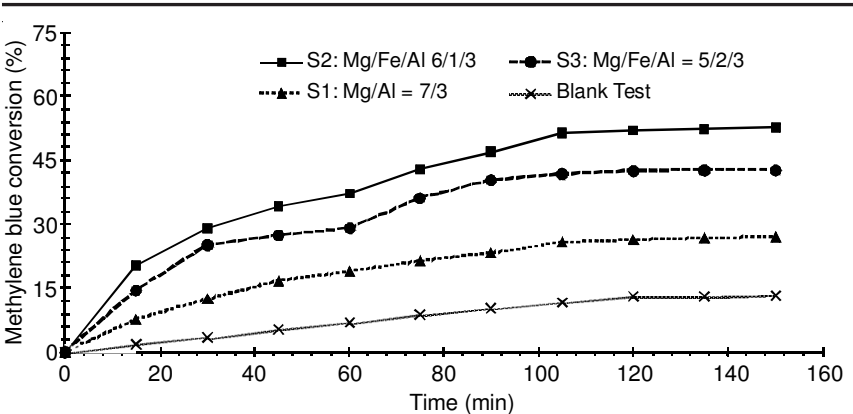

Fig. 5. Conversion of methylene blue on $\mathrm{Mg}-\mathrm{Fe}-\mathrm{Al}$ hydrotalcite catalysts ( $0.20 \mathrm{~g}$ of catalyst, $3000 \mathrm{ppm}$ of methylene blue, room temperature, under solar light)

it is expected that these ion species serve as active sites for oxidizing methylene blue by $\mathrm{H}_{2} \mathrm{O}_{2}$, as a traditional Fenton catalyst $^{28}$. Fig. 5 shows an increase in the methylene blue conversion with reaction time over the two $\mathrm{Fe}$-containing layered double hydroxide patterns ${ }^{27}$. Thus, ions really play important catalysts sites for decolorization of methylene blue. It is very interesting to see the conversion of methylene blue on the Fe-richest layered double hydroxide (sample S3) with higher surface area is somewhat lower than that over the Fe- poor one (sample S2) (Fig. 5 and Table-1). This is explained by the role of intra-layer iron hydrotalcite and the catalyst texture in the photocatalytic activity ${ }^{26}$. As indicated by XRD, the $\mathrm{Fe}$-rich layered double hydroxide (S3) may have some $\mathrm{FeO}_{\mathrm{x}}$ amorphous impurities which would not possibly work well for the conversion of methylene blue. In addition, this sample has larger domains that did not provide good contacting region between the reactant and active sites. Moreover, the effect of $\mathrm{Mg} / \mathrm{Al}$ ratio of the catalytic activity may not be ruled out $^{26,27,30}$. Therefore, the trend in variation of methylene blue over $\mathrm{Mg} / \mathrm{Fe} / \mathrm{Al}=5 / 2 / 3$ is below that on sample S2 (Fig. 5). To confirm this interpretation, we have investigated the catalytic activity at different conditions.

Fig. 6 displays the variation of methylene blue conversion versus retention time at $45^{\circ} \mathrm{C}$ while Fig. 7 represents experimental data under UV light at room temperature. Both Figs. 6 and 7 clearly indicate that the reaction variables have strongly affected the ability to decolorize methylene blue of $\mathrm{Mg}-\mathrm{Fe}-\mathrm{Al}$ hydrotalcite catalysts. Fortunately, methylene blue conversion follows exactly what we observed above (Fig. 5). The conversion of methylene blue over the examined hydrotalcite catalysts decreases in order of $(\mathrm{Mg} / \mathrm{Fe} / \mathrm{Al}=6 / 1 / 3)>(\mathrm{Mg} / \mathrm{Fe} / \mathrm{Al}=5 / 2 /$ $3)>(\mathrm{Mg} / \mathrm{Fe} / \mathrm{Al}=6 / 0 / 3)$. In the two latter cases, methylene blue conversion is quite higher. It reaches $75-90 \%$ after 40 50 min while the methylene blue conversion on the Fe-free hydrotalcite significantly changes. Thus, the Mg-Fe-Al hydrotalcite catalysts are rather active for the decolorization of methylene blue in aqueous solution.

\section{Conclusion}

Three Mg-Fe-Al hydrotalcite-like materials prepared by co-precipitation method were characterized and used as adsorbents/catalysts for the decolorization of aqueous methylene blue solution in the presence of a small amount of $\mathrm{H}_{2} \mathrm{O}_{2}$. All synthesized samples have well-crystallized hydrotalcite phases and uniform particles or plate-like shapes, porosity. The chemical composition has strongly affected the material

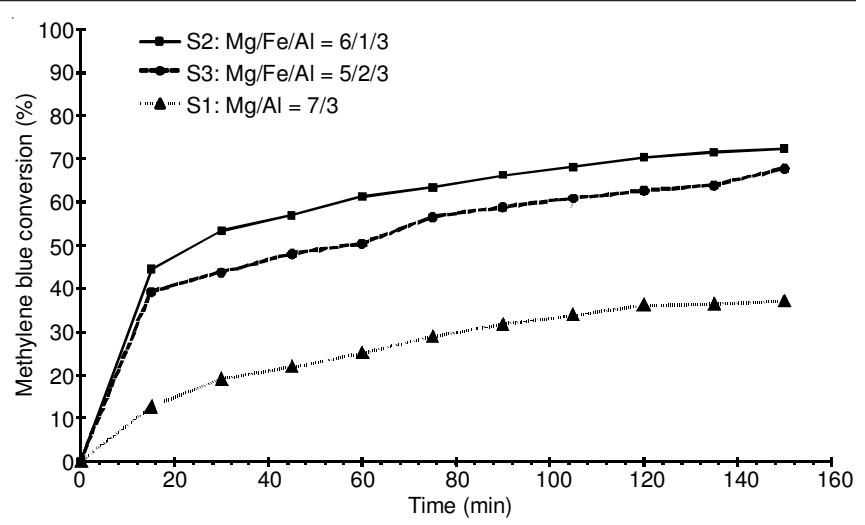

Fig. 6. Conversion of methylene blue on $\mathrm{Mg}-\mathrm{Fe}-\mathrm{Al}$ hydrotalcites $(0.20 \mathrm{~g}$ of catalyst, $3000 \mathrm{ppm}$ of methylene blue, $45^{\circ} \mathrm{C}$, under solar light)

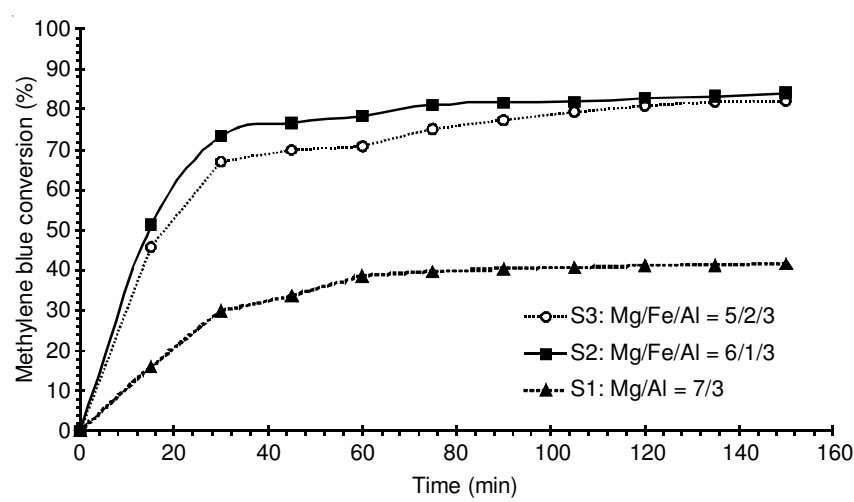

Fig. 7. Removal of methylene blue on Mg-Fe-Al hydrotalcites $(0.20 \mathrm{~g}$ of catalyst, $3000 \mathrm{ppm}$ of methylene blue, room temperature, under UV light)

texture. These layered double hydroxides are used as active catalysts for the decolorization of methylene blue in water. Our preliminary data indicated that $\mathrm{Mg}$-Al hydrotalcite possibly plays as an efficient adsorbent while $\mathrm{Mg}$-Fe-Al layered double hydroxides are active catalysts for the oxidation of methylene blue. The photocatalytic activity was found to be associated with the intra-lattice iron content, catalyst morphology, reaction conditions. The conversion of methylene blue was maintained at $55 \%$ under ambient conditions, but sharply increases to $78-90 \%$ after 45 min-on-time at $45^{\circ} \mathrm{C}$ or under UV light at room temperature.

\section{ACKNOWLEDGEMENTS}

This research is funded by Vietnam National Foundation for Science and Technology Development (NAFOSTED) under grant number 104.99-2011.50.

\section{REFERENCES}

1. F. Cavani, F. Trifiro and A. Vaccari, Catal. Today, 11, 173 (1991).

2. G.R. Williams and D. O'Hare, J. Mater. Chem., 16, 3065 (2006).

3. C.A. Antonyraj and S. Kannan, Appl. Catal. A, 338, 121 (2008).

4. K.K. Rao, M. Gravelle, J.S. Valente and F. Figueras, J. Catal., 173, 115 (1998).

5. A. Corma, V. Foner, R.M. Martin-Aranda and F. Rey, J. Catal., 134, 58 (1992).

6. P.C.H. Mitchell and S.A. Wass, Appl. Catal. A, 225, 153 (2002).

7. M.R. Morrill, N.T. Thao, H. Shou, D.J. Barton, D. Ferrari, R.J. Davis, P.K. Agrawal and C.W. Jones, Catal. Lett., 142, 875 (2012).

8. K. Schulze, W. Makowski, R.Chyzy and R. Dziembaj, Appl. Clay Sci., 18, 59 (2001)

9. C.X. Qi, J.C. Amphlett and B.A. Peppley, Appl. Catal. A, 302, 237 (2006). 
10. K.O. Christensen, D. Chen, R. Lodeng and A. Holmen, Appl. Catal. A, 314, 9 (2006).

11. S.K. Jana, Y. Kubota and T. Tatsumi, J. Catal., 247, 214 (2007).

12. D. Bianchi, M Bertoli, R. Tassinari, M. Ricci and R. Vignola, J. Mol. Catal. A, 200, 111 (2003).

13. Angelescu, O.D. Pavel, R. Birjega, M. Florea and R. Zavoianu, Appl. Catal. A, 341, 50 (2008).

14. I. Kirm, F. Medina, X. Rodrýguez, Y. Cesteros, P. Salagre and J. Sueiras, Appl. Catal. A, 272, 175 (2004).

15. M. Hadnadjev, T. Vulic, R. Marinkovic-Neducin, Y. Suchorski and H. Weiss, Appl. Surf. Sci., 254, 4297 (2008).

16. M.R. Schütz, A.E. Schedl, F.E. Wagner and J. Breu, Appl. Clay Sci., 54, 281 (2011)

17. G. Carija, R. Nakamura, T. Aida and H. Niiyama, Micropor. Mesopor. Mater., 47, 275 (2001).

18. I.M. Ahmed and M.S. Gasser, Appl. Surf. Sci., 259, 650 (2012).

19. N. Benselka-Hadj Abdelkader, A. Bentouami, Z. Derriche, N. Bettahar and L.-C. de Menorval, Chem. Eng. J., 169, 231 (2011).
20. A. Violante, M. Pucci, V. Cozzolino, J. Zhu and M. Pigna, J. Colloid Interf. Sci., 333, 63 (2009).

21. V. Rives, Mater. Chem. Phys., 75, 19 (2002).

22. A.G. Caporale, M. Pigna, J.J. Dynes, V. Cozzolino, J. Zhu and A. Violante, J. Hazard. Mater, 198, 291 (2011).

23. J.B. Condon, Surface Area and Porosity Determinations by Physisorption Measurements and Theory, The Netherlands, Elsevier B.V. p. 12 (2006).

24. D. Meloni, R. Monaci, V. Solinas, A. Auroux and E. Dumitriu, Appl. Catal. A, 350, 86 (2008).

25. M. Hajjaji, A. Alami and A. El Bouadili, J. Hazard. Mater., 135, 188 (2006).

26. L. Zhang, Y. Nie, C. Hu and X.X. Hu, J. Hazard. Mater, 190, 780 (2011).

27. C. Noubactep, J. Hazard. Mater, 166, 79 (2009).

28. K. Dutta, S. Mukhopadhyay, S. Bhattacharjee and B. Chaudhuri, J. Hazard. Mater., 84, 57 (2001).

29. I.A. Salem and M.S. El-Maazawi, Chemosphere, 41, 1173 (2000).

30. C. Namasivayam and S. Sumithra, J. Environ. Manage., 74, 207 (2005). 